\title{
Pressure Ulcer and Nutrition
}

\author{
Seied Hadi Saghaleini, Kasra Dehghan', Kamran Shadvar, Sarvin Sanaie², Ata Mahmoodpoor, Zohreh Ostadi \\ Department of Anesthesiology, Faculty of Medicine, Tabriz University of Medical Sciences, ${ }^{2}$ Tuberculosis and Lung Disease Research Center, Tabriz University of \\ Medical Sciences, Tabriz, ${ }^{1}$ Department of Anesthesiology, Faculty of Medicine, Urmia University of Medical Sciences, Urmia, Iran
}

\section{Abstract}

Pressure ulcers can diminish global life quality, contribute to rapid mortality in some patients and pose a significant cost to health-care organizations. Accordingly, their prevention and management are highly important. Nutritional deprivation and insufficient dietary intake are the key risk factors for the development of pressure ulcers and impaired wound healing. Unplanned weight loss is a major risk factor for malnutrition and pressure ulcer development. Suboptimal nutrition interferes with the function of the immune system, collagen synthesis, and tensile strength. No laboratory test can exactly define an individual's nutritional status. Although serum albumin, prealbumin, transferrin, and retinol-binding protein as well as anthropometric measures such as height, weight, and body mass index and the other laboratory values may be suitable to establish the overall prognosis, still they might not well represent the nutritional status. Although the ideal nutrient intake to encourage wound healing is unknown, increased needs for energy, protein, zinc, and Vitamins A, C, and E and also amino acids such as arginine and glutamine have been documented. Hydration plays a vital role in the preservation and repair of skin integrity. Dehydration disturbs cell metabolism and wound healing. Adequate fluid intake is necessary to support the blood flow to wounded tissues and to prevent additional breakdown of the skin. The main aim of the present article is to review the current evidence related to hydration and nutrition for bedsore prevention and management in adults.

Keywords: Management, nutrition, pressure ulcer

\section{INTRODUCTION}

The main aim of the present article is to review the current evidence related to hydration and nutrition for bedsore prevention and management in adults announced by the nutrition endorsements from the last National Pressure Ulcer Advisory Panel (NPUAP) and European Pressure Ulcer Advisory Panel guidelines for pressure ulcer treatment. ${ }^{[1]}$ Hydration and nutrition have an essential role in skin and tissue viability and help tissue repair in management of pressure ulcer. This article is concerned with the association between nutrition and prevention and cure of pressure ulcers. ${ }^{[2]}$ Mechanisms by which nutritional support helps prevent bedsore are not defined, but at least, it is well known that the nutritional status should be well promoted.

\section{Prevalence, Incidence, and Health-care Burden of Pressure Ulcers}

In the USA, approximately 1-3 million people develop pressure ulcers each year, ${ }^{[3]}$ and more than 2.5 million patients

\begin{tabular}{|l|l|}
\hline \multicolumn{3}{c|}{ Access this article online } \\
\hline Quick Response Code: & Website: \\
& www.ijccm.org \\
\cline { 2 - 2 } & \\
&
\end{tabular}

in the United States acute care services suffer from pressure ulcers, and 60,000 each year die from the complications of such ulcers. ${ }^{[4]}$ In the United States between 1990 and 2000, the NPUAP reported a prevalence rate of pressure ulcer ranging from $10 \%$ to $18 \%$ in general acute care, $2.3 \%$ to $28 \%$ in long-term care and up to $29 \%$ in home care, and $0 \%$ to $6 \%$ in rehabilitative care. ${ }^{[5,6]}$ Pressure ulcers can diminish global life quality because of pain, management procedures, and increased length of hospital stay. Furthermore, they contribute to rapid mortality in some patients. ${ }^{[7]}$ Therefore, any intervention that may assist to avoid pressure ulcers or to treat them may be important to decrease the cost of pressure ulcer care and increase life quality of affected individuals. ${ }^{[1]}$ Pressure ulcer management costs are a major problem to healthcare organizations. In the UK, the cost is estimated at $£ 1.4-£ 2.1$ billion annually ${ }^{[8]}$ and in the US is

Address for correspondence: Dr. Zohreh Ostadi, General ICU, Shohada Hospital, El-Goli Street, Tabriz, Iran. E-mail: zohreh_ostadi@yahoo.com

This is an open access journal, and articles are distributed under the terms of the Creative Commons Attribution-NonCommercial-ShareAlike 4.0 License, which allows others to remix, tweak, and build upon the work non-commercially, as long as appropriate credit is given and the new creations are licensed under the identical terms.

For reprints contact: reprints@medknow.com

How to cite this article: Saghaleini SH, Dehghan K, Shadvar K, Sanaie S, Mahmoodpoor A, Ostadi Z. Pressure ulcer and nutrition. Indian J Crit Care Med 2018;22:283-9. 
estimated at $\$ 1.6$ billion. ${ }^{[9]}$ In Australia, budgets spent per each patient admitted to Intensive Care Units (ICUs) have been around $\$ 18,964 .^{[10]}$ In the UK, the reported cost of care for pressure ulcers has been $4 \%$ of total healthcare costs. ${ }^{\left[{ }^{[8}\right.}$

\section{Research About Nutritional Status}

Nutritional deprivation and insufficient dietary intake are the key risk factors for the development of pressure ulcers and impaired wound healing. A number of studies including The National Pressure Ulcer Long-Term Care Study revealed that weight loss and inadequate nutritional intake were associated with a higher risk of developing pressure ulcers. ${ }^{[11-13]}$ Stratton et al. in 2005 in a systematic review and meta-analysis investigated the advantages of nutritional support in patients at risk of developing pressure ulcers. Oral and enteral support was their main focus in bedsore prevention. ${ }^{[14]}$ Fry et al. described that preceding underfeeding and/or weight loss was a positive prognostic indicator for pressure ulcers. ${ }^{[15]}$ In Japan, Iizaka et al. observed that $58.7 \%$ of patients at age 65 or older with pressure ulcers receiving home care suffered from malnourishment. ${ }^{[16]}$ Blanc et al. showed that age, particularly 65 years and higher, is a risk factor for the development of pressure ulcer. ${ }^{[17]}$ Cox proposed that malnutrition is a state of disproportion in energy, protein, and other nutrients that leads to harmful effects on body structures and tissues. ${ }^{[18]}$

In a study by Montalcini et al., it was observed that a serum albumin level of $<3.1 \mathrm{~g} / \mathrm{dl}$ predicted pressure ulcer formation and was associated with higher mortality. ${ }^{[19]}$ Significant association between unintended weight loss (5\%-10\%) and development of pressure ulcers was shown by Shahin et al. They showed this association in a population of individuals in nursing homes and hospitals in Germany. The fact that patients with malnutrition and multiple comorbidities were at increased risk for developing a pressure ulcer was asserted in 2014 National Pressure Ulcer Consensus Conference. ${ }^{[20,21]}$ New onset weight loss has been identified as a risk factor for mortality in elderly patients. ${ }^{[22]}$ Two studies on individuals in long-term care facilities showed that a 5\% decrease in body weight occurring over 30 days was associated with a higher mortality risk. ${ }^{[23,24]}$

\section{NUtRition And Inflammation}

Stress during critically illness is associated with three distinct metabolic phases: the acute, hypermetabolic, and recovery phases. ${ }^{[25]}$ The clinical consequences of metabolic response during acute phase include preferential use of carbohydrates, loss of muscle mass and sarcopenia, and stress-induced hyperglycemia. ${ }^{[2]}$ Hence, physicians should consider the physiological changes during stress and provide less than maximum amount of required energy $(20 \mathrm{kcal} / \mathrm{kg})$ while sufficient calorie intake (one-third fat and two-thirds carbohydrate and a protein intake of almost $1.5 \mathrm{~g} / \mathrm{kg}$ ) is essential during hypermetabolic and recovery stages. All physicians should monitor and optimize nutrition management based on changes in the body composition and behavior.

\section{Malnutrition and Pressure Ulcer}

Nutritional status plays a central role in the process of wound healing. Malnutrition accompanies a poor outcome and brings about higher morbidity and mortality. Malnutrition should be recognized rapidly and treated accordingly in all patients suffering from pressure ulcers. Malnutrition impedes pressure ulcer healing. Unplanned weight loss - which is defined as $5 \%$ weight loss within 1 month or $10 \%$ within 6 months by the minimum data set - is a major risk factor for malnutrition and pressure ulcer development. ${ }^{[27]}$ Some of the causes of malnutrition include increased nutritional requirements, difficulty swallowing and chewing, and decreased intake of food and advanced age. Malnutrition reduces the body's ability to fight against infections and has an adverse impact on pressure ulcer healing. ${ }^{[1]}$ Table 1 shows criteria used for the diagnosis of severe malnutrition in critically ill patients. The patient should have two of six clinical features to fulfill the criteria. ${ }^{[18]}$ Other medical conditions may disturb healing of pressure ulcer; cachexia is a condition which may affect the healing of pressure ulcers. "Cachexia is a complex metabolic syndrome associated with underlying sickness and characterized by loss of muscle and fat mass." ${ }^{\text {[28] }}$ Weight loss is the prominent feature of cachexia (corrected for fluid retention). Wasting diseases are commonly concomitant with anorexia, inflammation, insulin resistance, and augmented breakdown of muscle protein and are different from starvation, age-related loss of muscle mass, primary depression, malabsorption, and hyperthyroidism. They are mostly related with morbidity. ${ }^{[28]}$ Three important phases of wound healing are inflammatory phase, proliferative phase, and remodeling phase. These phases although distinct are overlapping. Suboptimal nutrition interferes with the function of the immune system, collagen synthesis, and tensile strength. ${ }^{[18]}$ Chronic wounds are characterized by features such as a prolonged inflammatory response, low levels of growth factors, and high contamination with microorganisms. Chronic wounds can induce a catabolic state, protein-calorie malnutrition, and dehydration all of which as a result of a long-lasting inflammatory state. Hypermetabolism is an

\begin{tabular}{ll}
\hline $\begin{array}{l}\text { Table 1: Clinical characteristics of severe malnutrition in } \\
\text { the setting of acute illness or injury }\end{array}$ \\
\hline $\begin{array}{l}\text { Clinical } \\
\text { characteristic }\end{array}$ & Definition of severe malnutrition \\
\hline $\begin{array}{l}\text { Weight loss } \\
\text { Body fat }\end{array}$ & $\begin{array}{l}\text { Moderate loss of subcutaneous fat (triceps, } \\
\text { intercostal muscles) } \\
\text { Energy intake }\end{array}$ \\
$\begin{array}{l}\text { Fluid } \\
\text { accumulation }\end{array}$ & $\begin{array}{l}\text { Moderate to severe (generalized or local) } \\
\text { Muscle mass }\end{array}$ \\
$\begin{array}{l}\text { Moderate muscle loss (pectorals, deltoids, } \\
\text { Reduced grip } \\
\text { strength }\end{array}$ & $\begin{array}{l}\text { Measurably reduced (not practical to test in an } \\
\text { unresponsive critical care patient) }\end{array}$ \\
\hline
\end{tabular}


important concern. This is a response to events such as infection, trauma, severe illness, pressure ulcers, and several others. In this state, the body consumes calories rapidly, first drawing from existing glycogen stores, and later from protein stores to keep up with energy requirements of the body. Interleukin (IL) 1, 6 and pro-inflammatory cytokines cause impaired albumin production, decrease nitrogen preservation, muscle wasting, and anorexia. ${ }^{[29]}$

\section{Biochemical Data for Nutrition Screening and AsSESSMENT}

An important part of nutritional assessment is "biological data analysis." While laboratory tests may help to assess nutrition problems in patients at risk or those who are actually affected by pressure ulcers, no laboratory test can exactly define an individual's nutritional status. Therefore, at the moment, there are no ideal laboratory tests to detect malnutrition. Although serum albumin, prealbumin, transferrin, and retinol-binding protein as well as anthropometric measures such as height, weight, and body mass index and the other laboratory values may be suitable to establish the overall prognosis, still they might not well represent the nutritional status. ${ }^{[30,31]}$ Serum albumin is not a sensitive indicator of malnutrition because its levels are influenced by a variety of nutritionally unrelated factors such as protein-losing states, hepatic dysfunction, acute infection, and inflammation. Bluestein and Javaheri ${ }^{[32]}$ introduced some useful indicators that help to detect protein-calorie malnourishment in patients with pressure ulcers including involuntary weight loss of $5 \%$ or more in the previous month or of $10 \%$ or more in the previous 6 months, weight fewer than $80 \%$ of ideal body weight, serum albumin level $<3.5 \mathrm{~g} / \mathrm{dl}$ ( $35 \mathrm{~g} / \mathrm{L})$, prealbumin level fewer than $15 \mathrm{mg} / \mathrm{dl}(150 \mathrm{mg} / \mathrm{L})$, transferrin level fewer than $200 \mathrm{mg} / \mathrm{dl}$ $(2 \mathrm{~g} / \mathrm{L})$, and total lymphocyte counts fewer than 1500 per $\mathrm{mm}^{3}$ $\left(1.50 \times 10^{9} / \mathrm{L}\right)$.

Associations have been discovered among old age, malnutrition, and the development of pressure ulcers. ${ }^{[33]}$ Proper nutritional support plays an essential role in preventing pressure ulcers and stimulating wound healing. ${ }^{[34]}$ Several conditions such as heart failure, inflammatory and catabolic states, respiratory diseases, dysphagia, dental malocclusion, and chewing difficulties and even decreased sense of smell and taste and certain medications may eventually lead to undernourishment. ${ }^{[35]}$ The adverse effects of malnutrition contain organ dysfunction, compromised collagen synthesis (that reduces the stretchability of skin), weakness of the immune system, and decreased activity of antioxidant mechanisms (leading to accumulation of free radicals) and increasing risk of infection. Reduced tensile strength of the damaged skin interferes with healing of the damaged skin. It increases the risk of wound dehiscence and infection. Chronic pressure ulcers lasting longer than 6 weeks are in a critical phase where neutrophils battle to clear the wound from bacteria. This is a demanding process, and patients are at increased need of protein and energy supplies.
These requirements are not supported wound healing will be jeopardized. ${ }^{[33]}$ The subjective global assessment (SGA) is a method of assessment for the evaluation of nutritional status based on medical history and physical examination. This method was developed and proposed by Baker and co-investigators in gastrointestinal surgery patients. The method was then revised by Serpa et al. for both surgical and nonsurgical patients. ${ }^{[36]}$ The SGA forms contain basic information from the medical history (weight changes and presence of a disease and its relation to nutritional requirements), physical examinations (loss of subcutaneous fat, muscle wasting, and presence of ascites and ankle, and sacral edema), dietary intake, presence of gastrointestinal symptoms, and functional capacity. Results of this study reveal that serum albumin levels and SGA score were the most powerful predictors of pressure ulcer development. ${ }^{\left[{ }^{36]}\right.}$ Recently, the NUTRIC score is designed to quantify the risk of critically ill patients developing adverse events that may be modified by aggressive nutrition therapy. It consisted of APACHE and sequential organ failure assessment scores, age, number of comorbidities, days from hospital to ICU admission, and IL-6 levels. As IL-6 contributes very little to overall prediction of score and is not routinely available, the total score could be calculated without considering IL-6.

\section{Nutrition and Wound Healing}

Although the ideal nutrient intake to encourage wound healing is unknown, increased needs for energy, protein, zinc, and Vitamins $\mathrm{A}, \mathrm{C}$, and $\mathrm{E}$ have been documented. High-protein oral nutritional supplements are effective in reducing the incidence of pressure ulcers by $25 \%$ in patients at risk. Energy, protein, arginine, and micronutrients (Vitamins A, C, and zinc) are all vital in the wound healing. Proteins are the most important macronutrients since it is indispensable for the repair of tissues. Proteins are vital in keeping a positive nitrogen balance and for all stages of the wound healing including fibroblast proliferation, collagen synthesis, angiogenesis, and immune function. In enteral formulations, protein can be in the form of intact proteins, hydrolyzed proteins, or free amino acids. The NPUAP/EPUAP recommends a global protein intake for pressure ulcer healing of 1.25 to $1.5 \mathrm{~g} / \mathrm{kg}$ of body weight per day. For patients with Stage III/IV pressure ulcers, the proposed level is $1.5-2.0 \mathrm{~g} / \mathrm{kg}$, depending on the size of the pressure ulcer, and the total protein loss from draining wounds. ${ }^{[18]}$ In a study, the group receiving higher protein ( $1.8 \mathrm{~g}$ protein per $\mathrm{kg}$ body weight) demonstrated nearly a two-fold greater rate of healing than those randomized to lower protein intake (1.2 g protein per $\mathrm{kg}$ body weight). ${ }^{[37]}$

Increased protein intake has been linked to enhanced healing rates. ${ }^{[38,39]}$ Dietary protein is principally important in elderly owing to body composition changes that occur with aging and reduced activity levels. Recent studies indicate that the basic requirement for exogenous protein in elderly is a minimum of $1.0 \mathrm{~g} / \mathrm{kg}$ of body weight rather 
than $0.8 \mathrm{~g} / \mathrm{kg}$ for good adults. ${ }^{[40]}$ The recommendation for protein supplementation varies according to the stage of ulcer; in Stage I and Stage II, $1-1.4 \mathrm{~g} / \mathrm{kg}$ and in Stage III and Stage IV, $1.5-2.0 \mathrm{~g} / \mathrm{kg}$, and the maximum requirement is $2.2 \mathrm{~g} / \mathrm{kg}{ }^{[18]}$ Another study investigated nitrogen balance and proposed an average protein requirement of $0.95 \mathrm{~g} / \mathrm{kg}$. The safety of these requirements also needs to be evaluated because excessive protein intake could have negative effects on fragile older patients such as increased urea synthesis in the liver and decreased renal function. The estimated energy requirement $(30 \mathrm{kcal} / \mathrm{kg})$ and the average protein requirement $(0.95 \mathrm{~g} / \mathrm{kg})$ had adequate clinical validity as minimum requirements for maintaining nutritional status and accelerating wound healing in older patients with pressure ulcers. ${ }^{[37]}$ Patients with chronic pressure ulcers lose protein through wound exudate. This reduces collagen development and impedes wound healing. Wound healing needs energy mainly for collagen synthesis. To prevent protein-energy malnutrition and improve wound healing, the diet should be adequate in energy in the form of carbohydrate and fat and protein. Macronutrients are found in oral, enteral, and parenteral formulations in the forms of carbohydrates, fats, and proteins. Glucose acts as a basis of energy for cellular activity. Approximately $35 \%-55 \%$ of most standard enteral feeding formulations contain carbohydrates that are the primary macronutrient and the main energy source. Carbohydrates also increase the osmolality of formulas, assist in digestibility, and improve sweetness and add to the taste of the formula ${ }^{[18]}$ Fat plays a significant role in cell membrane synthesis, is a source of energy, and is a critical component in the development of inflammatory mediators and clotting elements. Amino acids are the basic structures of proteins. Arginine and glutamine are essential amino acids in severe stress phase such as trauma, sepsis, and/or pressure ulcers. ${ }^{[1]}$ Arginine excites insulin secretion, enhances wound healing, and prevents pressure ulcer development. It stimulates the transport of amino acids into tissue cells and supports the manufacturing of proteins in the cell. Arginine acts as a substrate for protein synthesis, cell proliferation, collagen deposition, T-lymphocyte function, and promotes positive nitrogen balance. It is also the biological precursor for nitric oxide which has potent vasodilatory, antibacterial and angiogenic properties; all of these properties are important for wound healing. In diabetes, nitric oxide synthesis is reduced in the wound environment and as arginine is the lone substrate for nitric oxide synthesis, it has been hypothesized that arginine supplementation could increase wound healing by enhancing nitric oxide production. ${ }^{[37]}$ The maximum safe dose for arginine supplementation for wound healing has not yet been established. A total of $30 \mathrm{~g}$ of arginine aspartate, containing $17 \mathrm{~g}$ of arginine, has been taken orally in three divided doses for 2 weeks without any complication. Furthermore, a dose of $36.2 \mathrm{~g}$ of L-arginine $\mathrm{HCl}$ has been tried orally daily for 5 days with no adverse effects. ${ }^{[41]}$ Amino acid supplementation with arginine and glutamine may be considered in patients with existing pressure ulcers; however, evidence supporting the role of these agents in prevention or healing of pressure ulcers has remained inadequate. ${ }^{[18]}$ Caution should be exercised with arginine supplementation in critically ill patients with sepsis. Arginine acid may contribute to hemodynamic instability in septic patients. ${ }^{[18]}$ Glutamine acts as a fuel source for fibroblasts and epithelial cells. The maximum safe dose for glutamine supplementation has been established at $0.57 \mathrm{~g} /$ $\mathrm{kg}$ of body weight per day. ${ }^{[42]}$ Meanwhile, supplemental glutamine has not been shown to increase wound healing. ${ }^{[43]}$ Additional studies are needed to investigate the effects of arginine and glutamine on pressure ulcer healing. A lot of micronutrients have antioxidant properties, promote collagen synthesis, and augment the immune system response. In ischemic tissue within pressure ulcers, large quantities of free radicals are formed. Some micronutrients, such as selenium and the Vitamins A, C, and E, may deactivate free radicals and potentially accelerate wound healing. ${ }^{[34]}$ If oral intake is insufficient or unusable, enteral or parenteral feeding is considered. The goal is to maintain a positive nitrogen balance (almost $30-35 \mathrm{kcal} / \mathrm{kg} /$ day and $1.25-1.5 \mathrm{~g}$ of protein per kg per day). Protein supplements, Vitamin C, and zinc should be used if intake is inadequate and deficit is present, while data supporting their efficacy in accelerating healing have been unreliable. ${ }^{[44]}$

Vitamin A stimulates epithelialization and the immune system response. Vitamin A promotes aggregation of monocytes and macrophages, increases the number of macrophages and monocytes in the wound, supports mucosal and epithelial surfaces, increases collagen formation, protects against adverse effects of glucocorticoids, chemotherapy, radiation, and diabetes. Normal daily Vitamin A requirement in men is $3333 \mathrm{IU} / \mathrm{d}$ and in women is $2310 \mathrm{IU} / \mathrm{d}$. Prophylactic $10000-15000 \mathrm{IU} / \mathrm{d}$ for 1 week in patients taking steroids should be considered. Dosing for pressure ulcer management in all stages are 10,000-50,000 IU/d orally for injured or severely malnourished patients, and maximum dose is 25,000-50,000 IU/d for 10-14 days. Vitamin A deficiency may lead to altered immune function, impaired collagen deposition, and delayed wound healing. Adverse effects of Vitamin A are dry mucosal membranes, vomiting, headache, liver damage, alopecia, muscle or bone pain, bleeding, and coma. Renal failure increases the risk of toxicity. ${ }^{[18]}$

Vitamin C increase iron absorption. It increases resistance to infection by promoting migration of white blood cells to the wound. Vitamin C promotes neutrophil and fibroblast activity and is required for angiogenesis. Vitamin $\mathrm{C}$ is a cofactor for hydroxylation of proline and lysine in the process of collagen formation. Normal daily Vitamin $\mathrm{C}$ requirements in nonsmoker men and women are 90 and $75 \mathrm{mg} /$ d, respectively. Dosing for pressure ulcer management in Stage I and Stage II ulcers is $100-200 \mathrm{mg} / \mathrm{d}$ and in Stage III and Stage IV ulcers is $1000-2000 \mathrm{mg} / \mathrm{d}$. In patients with renal failure, the dose is adjusted to $60-100 \mathrm{mg} / \mathrm{d}$ to diminish the risk of stone formation. Vitamin $\mathrm{C}$ deficiency leads to impaired fibroblast 
activity and consequently impaired collagen synthesis and capillary fragility. Moreover, Vitamin C deficiency decreases the capacity to fight infections by impairing the immune system function. ${ }^{[45]} \mathrm{An}$ adverse effect of excess Vitamin $\mathrm{C}$ is renal stone formation. ${ }^{[18]}$ Maximum daily dose of Vitamin $\mathrm{C}$ is $2000 \mathrm{mg}$. Yet, high doses of Vitamin C have not been shown to accelerate wound healing. ${ }^{[46]}$

Copper has a role in collagen cross linking that is required for the reconstruction of tissues and iron improves tissue oxygen delivery. Manganese has tissue regenerating roles. Zinc is an antioxidant mineral that plays role in the production of proteins (such as collagen), DNA and RNA, and cell proliferation. ${ }^{[47]}$ Zinc is transported primarily by albumin; therefore, zinc absorption reduces when plasma albumin declines, for example, in protein energy malnutrition, trauma, sepsis, or infection. Zinc is an essential element required for cell replication and growth and protein synthesis. Daily requirements for zinc in men and women are 11 and $8 \mathrm{mg} / \mathrm{d}$, respectively. Whenever clinical signs of zinc deficiency are present, zinc should be supplemented no further than $40 \mathrm{mg}$ of elemental zinc per day ${ }^{[48]}$ and should be stopped when the deficiency is resolved. Deficiencies may be seen in diarrhea, malabsorption, hypermetabolic states, stress, sepsis, burns, and ulcers and can lead to loss of appetite and abnormal taste, which can hinder nutritional intake. In management of the patient with any stage of pressure ulcer and zinc deficiency, the recommended dose for zinc supplement is $220 \mathrm{mg} / \mathrm{d}$ for 10-14 days. Zinc supplements are insoluble and poor absorbed. For this reason, requirement of zinc in small intestinal fluid losses is $12.2 \mathrm{mg} / \mathrm{L}$ of lost, in excess stool output is $17.1 \mathrm{mg}$ of zinc per kilogram of stool and in patient with ileostomy is $17.1 \mathrm{mg}$ of zinc per kilogram of ileostomy drainage. Severe zinc deficiency needs continuous infusion of intravenous zinc in dose of $50-100 \mathrm{mg} / \mathrm{d}$, if tolerated, with close monitoring of the patient. ${ }^{[18]}$ High-dose zinc supplementation (above $40 \mathrm{mg} /$ day) is not indicated because it can unfavorably affect copper status possibly resulting in anemia. ${ }^{[49,50]}$ Adverse effects of excessive zinc include poor wound healing - due to decreased immune function - disruption of normal phagocytic activity, impaired neutrophil and lymphocyte function, copper- and calcium-binding interactions - leading to copper and calcium deficiencies - and gastrointestinal tract problems such as nausea, vomiting, and diarrhea.

Vitamin $\mathrm{K}$ is critical for the production of prothrombin and other clotting proteins produced in liver. These proteins are required for the initial phases of wound healing.

Hydration plays a vital role in the preservation and repair of skin integrity. Dehydration disturbs cell metabolism and wound healing. Adequate fluid intake is necessary to support the blood flow to wounded tissues and to prevent the additional breakdown of skin. ${ }^{[34]}$ The National Institute for Health and Care Excellence 2006 recommends 30-35 ml/kg of body weight fluid and current recommendations of ASPEN for water intake are $30 \mathrm{ml} / \mathrm{kg}$ of body weight or $1.0-1.5 \mathrm{ml}$ per calorie expended. For the healing of pressure ulcers, $30-40 \mathrm{ml} / \mathrm{kg}$ or $1500 \mathrm{ml} / \mathrm{d}$ is recommended. Fluid replacement also depends on the volume of losses experienced by the patient (e.g., draining wounds, fever, and gastrointestinal losses) and the patient's comorbid conditions such as renal or cardiac disease. ${ }^{[18]}$ Patients with pressure ulcers may have additional fluid requirements since fluid may be lost via wound exudate. Patients, who use pressure-relieving air mattresses, are prone to excessive sweating and may need extra fluid to compensate for excess fluid loss.

Another adjuvant therapy in malnourished old aged or in patients with hypercatabolism states is ornithine alpha-ketoglutarate (OKG). OKG is a precursor of different amino acids that acts in the process of healing. The efficacy of $\mathrm{OKG}$ on the size reduction of pressure ulcer after 6 weeks of treatment is determined in the study by Meaume et al. They evaluate 160 patients aged over 60 years with a heel pressure ulcer at Stage II or Stage III for 6 weeks and analysis on two subgroups of patients according to the mean ulcer area, i.e., above or below $8 \mathrm{~cm}^{2}$. Results of this trial support a probable benefit of OKG (10 g/day) in patients with pressure ulcers $\leq 8 \mathrm{~cm}^{2}$ surface area in elderly population when associated with debridement together with wound management strategies. ${ }^{[49]}$

While the optimal nutrient intake to promote wound healing is unknown, increased needs for energy, protein, zinc, and Vitamins A, C, and E have been documented. High-protein oral nutritional supplements have been shown to effectively reduce the incidence of pressure ulcers in patients at risk by $25 \% .^{[35]}$

Nurses are frontline caregivers important to screening, assessment, and management of pressure ulcers. Early referral to dietician, skilled physician is the first step in improving the outcome of patients at risk of pressure ulcers. In patients with pressure ulcers, frequent skin inspection coupled with low air loss support surface in addition to providing adequate nutritional supplementation is recommended. ${ }^{[18]}$

Recent ESPEN guideline mentioned that in polymorbid medical patients with bedsore, specific amino acids such as arginine, glutamine, and $\beta$-hydroxy $\beta$-methylbutyrate can be added to oral/enteral foods to accelerate the healing of bedsores. ${ }^{[51]}$

Because of high burden of cost, healing and most importantly prevention of bedsores in critically ill patients is very important. Assessment and provision of appropriate nutrition based on evidence-based nutritional guidelines should be considered as an essential ingredient of medical management. Hence, appropriate screening for nutritional status, collaboration with skilled dietician, and administration of specialized formula consisted of macro and micronutrients are important aspects of pressure sore management in critically ill patients. 


\section{Financial support and sponsorship}

Nil.

\section{Conflicts of interest}

There are no conflicts of interest.

\section{RefERENCES}

1. Dorner B, Posthauer ME, Thomas D; National Pressure Ulcer Advisory Panel. The role of nutrition in pressure ulcer prevention and treatment: National Pressure Ulcer Advisory Panel white paper. Adv Skin Wound Care 2009;22:212-21. doi: 10.1097/01.ASW.0000350838.11854.0a.

2. Posthauer ME, Banks M, Dorner B, Schols JM. The role of nutrition for pressure ulcer management: National pressure ulcer advisory panel, European pressure ulcer advisory panel, and pan pacific pressure injury alliance white paper. Adv Skin Wound Care 2015;28:175-88.

3. Lyder CH, Yu C, Stevenson D, Mangat R, Empleo-Frazier O, Emerling J, et al. Validating the Braden scale for the prediction of pressure ulcer risk in blacks and Latino/Hispanic elders: A pilot study. Ostomy Wound Manage 1998;44:42S-9S.

4. Strategies for Preventing Pressure Ulcers, Joint Commission Perspectives on Patient Safety. Vol. 8; 2008. p. 5-7.

5. Pressure ulcers in America: prevalence, incidence, and implications for the future. An executive summary of the National Pressure Ulcer Advisory Panel monograph. Adv Skin Wound Care. 2001;14:208-15.

6. Lyder $\mathrm{CH}$. Pressure ulcer prevention and management. JAMA 2003;289:223-6.

7. Thomas DR, Goode PS, Tarquine PH, Allman RM. Hospital-acquired pressure ulcers and risk of death. J Am Geriatr Soc 1996;44:1435-40.

8. Bennett G, Dealey C, Posnett J. The cost of pressure ulcers in the UK. Age Ageing 2004;33:230-5.

9. Whittington K, Patrick M, Roberts JL. A national study of pressure ulcer prevalence and incidence in acute care hospitals. J Wound Ostomy Continence Nurs 2000;27:209-15.

10. Graves N, Birrell F, Whitby M. Effect of pressure ulcers on length of hospital stay. Infect Control Hosp Epidemiol 2005;26:293-7.

11. Horn SD, Bender SA, Ferguson ML, Smout RJ, Bergstrom N, Taler G, et al. The national pressure ulcer long-term care study: Pressure ulcer development in long-term care residents. J Am Geriatr Soc 2004;52:359-67.

12. Guenter P, Malyszek R, Bliss DZ, Steffe T, O’Hara D, LaVan F, et al. Survey of nutritional status in newly hospitalized patients with stage III or stage IV pressure ulcers. Adv Skin Wound Care 2000;13:164-8.

13. Mathus-vliegen E.M.H. Nutritional status, nutrition and pressure ulcers. Nutr Clin Pract 2001;16:286-91.

14. Stratton RJ, Ek AC, Engfer M, Moore Z, Rigby P, Wolfe R, et al. Enteral nutritional support in prevention and treatment of pressure ulcers: A systematic review and meta-analysis. Ageing Res Rev 2005;4:422-50.

15. Fry DE, Pine M, Jones BL, Meimban RJ. Patient characteristics and the occurrence of never events. Arch Surg 2010;145:148-51.

16. Iizaka S, Okuwa M, Sugama J, Sanada H. The impact of malnutrition and nutrition-related factors on the development and severity of pressure ulcers in older patients receiving home care. Clin Nutr 2010;29:47-53.

17. Blanc G, Meier MJ, Stocco JG, Roehrs H, Crozeta K, Barbosa DA, et al. Effectiveness of enteral nutritional therapy in the healing process of pressure ulcers: A systematic review. Rev Esc Enferm USP 2015;49:152-61.

18. Cox J, Rasmussen L. Enteral nutrition in the prevention and treatment of pressure ulcers in adult critical care patients. Crit Care Nurse 2014;34:15-27.

19. Montalcini T, Moraca M, Ferro Y, Romeo S, Serra S, Raso MG, et al. Nutritional parameters predicting pressure ulcers and short-term mortality in patients with minimal conscious state as a result of traumatic and non-traumatic acquired brain injury. J Transl Med 2015;13:305.

20. Banks MD, Graves N, Bauer JD, Ash S. The costs arising from pressure ulcers attributable to malnutrition. Clin Nutr 2010;29:180-6.

21. Edsberg LE, Langemo D, Baharestani MM, Posthauer ME, Goldberg M.
Unavoidable pressure injury: State of the science and consensus outcomes. J Wound Ostomy Continence Nurs 2014;41:313-34.

22. Thomas DR. Unintended weight loss in older adults. Aging Health 2008;4:191-200

23. Ryan C, Bryant E, Eleazer P, Rhodes A, Guest K. Unintentional weight loss in long-term care: Predictor of mortality in the elderly. South Med J 1995;88:721-4.

24. Sullivan DH, Johnson LE, Bopp MM, Roberson PK. Prognostic significance of monthly weight fluctuations among older nursing home residents. J Gerontol A Biol Sci Med Sci 2004;59:M633-9.

25. McHoney M, Eaton S, Pierro A. Metabolic response to surgery in infants and children. Eur J Pediatr Surg 2009;19:275-85.

26. Lheureux O, Preiser JC. Role of nutrition support in inflammatory conditions. Nutr Clin Pract 2017;32:310-7.

27. Kennerly S, Batchelor-Murphy M, Yap TL. Clinical insights: Understanding the link between nutrition and pressure ulcer prevention. Geriatr Nurs 2015;36:477-81.

28. Evans WJ, Morley JE, Argilés J, Bales C, Baracos V, Guttridge D, et al. Cachexia: A new definition. Clin Nutr 2008;27:793-9.

29. MacIntosh C, Morley JE, Chapman IM. The anorexia of aging. Nutrition 2000;16:983-95

30. Covinsky KE, Covinsky MH, Palmer RM, Sehgal AR. Serum albumin concentration and clinical assessments of nutritional status in hospitalized older people: Different sides of different coins? J Am Geriatr Soc 2002;50:631-7.

31. Ferguson RP, O'Connor P, Crabtree B, Batchelor A, Mitchell J, Coppola D, et al. Serum albumin and prealbumin as predictors of clinical outcomes of hospitalized elderly nursing home residents. J Am Geriatr Soc 1993;41:545-9.

32. Bluestein D, Javaheri A. Pressure ulcers: Prevention, evaluation, and management. Am Fam Physician 2008;78:1186-94.

33. Mathus-Vliegen EM. Old age, malnutrition, and pressure sores: An ill-fated alliance. J Gerontol A Biol Sci Med Sci 2004;59:355-60.

34. Todorovic V. Food and wounds: nutritional factors in wound formation and healing. Br J Community Nurs 2002:43-4.

35. Raffoul W, Far MS, Cayeux MC, Berger MM. Nutritional status and food intake in nine patients with chronic low-limb ulcers and pressure ulcers: Importance of oral supplements. Nutrition 2006;22:82-8.

36. Serpa LF, Santos VL. Validity of the Braden nutrition subscale in predicting pressure ulcer development. J Wound Ostomy Continence Nurs 2014;41:436-43.

37. Crowe T. Nutrition therapy in the prevention and treatment of pressure ulcers. Wound Practice Res 2009;17:90-9.

38. Hartgrink HH, Wille J, König P, Hermans J, Breslau PJ. Pressure sores and tube feeding in patients with a fracture of the hip: A randomized clinical trial. Clin Nutr 1998;17:287-92.

39. Breslow RA, Bergstrom N. Nutritional prediction of pressure ulcers. J Am Diet Assoc 1994;94:1301-4.

40. Chernoff R. Protein and older adults. J Am Coll Nutr 2004;23:627S-30S

41. Langer G, Schloemer G, Knerr A, Kuss O, Behrens J. Nutritional interventions for preventing and treating pressure ulcers. Cochrane Database Syst Rev 2003;(4):CD003216.

42. Ziegler TR, Benfell K, Smith RJ, Young LS, Brown E, Ferrari-Baliviera E, et al. Safety and metabolic effects of L-glutamine administration in humans. JPEN J Parenter Enteral Nutr 1990;14:137S-46S.

43. McCauley R, Platell C, Hall J, McCulloch R. Effects of glutamine infusion on colonic anastomotic strength in the rat. JPEN J Parenter Enteral Nutr 1991;15:437-9

44. Royal College of Nursing (UK). The Management of Pressure Ulcers in Primary and Secondary Care: A Clinical Practice Guideline [Internet] London: Royal College of Nursing (UK); 2005.

45. Collins N. The facts about vitamin $\mathrm{C}$ and wound healing. Ostomy Wound Manage. 2009;55:8-9.

46. Vilter RW. Nutritional aspects of ascorbic acid: Uses and abuses. West J Med 1980;133:485-92.

47. Stephens P, Thomas DW. The cellular proliferative phase of the wound repair process. J Wound Care 2002;11:253-61.

48. Osland EJ, Ali A, Isenring E, Ball P, Davis M, Gillanders L.Australasian Society for Parenteral and Enteral Nutrition guidelines for supplementation of trace elements during parenteral nutrition. Asia Pac 
J Clin Nutr. 2014;23:545-54.

49. Meaume S, Kerihuel JC, Constans T, Teot L, Lerebours E, Kern J, et al. Efficacy and safety of ornithine alpha-ketoglutarate in heel pressure ulcers in elderly patients: Results of a randomized controlled trial. J Nutr Health Aging 2009;13:623-30.

50. Haesler E. Prevention and Treatment of Pressure Ulcers: Clinical
Practice Guideline. National Pressure Ulcer Advisory Panel, European Pressure Ulcer Advisory Panel and Pan Pacific Pressure Injury Alliance; 2014.

51. Gomes F, Schuetz P, Bounoure L, Austin P, Ballesteros-Pomar M, Cederholm $\mathrm{T}$, et al. ESPEN guidelines on nutritional support for polymorbid internal medicine patients. Clin Nutr 2018;37:336-53. 